\title{
Verification of Stress Transformation in Anisotropic Material Additively Manufactured by Fused Deposition Modeling (FDM)
}

\section{Hossein Sehhat ( $\square$ hsehhat@mst.edu )}

University of Missouri Rolla: Missouri University of Science and Technology https://orcid.org/0000-0002-7013-1642

Ali Mahdianikhotbesara

Farzad Yadegari

\section{Research Article}

Keywords: Fused Deposition Modeling (FDM), Anisotropic, Stress Transformation, Mechanical Properties, Design of Experiments (DOE), Additive Manufacturing

Posted Date: September 13th, 2022

DOI: https://doi.org/10.21203/rs.3.rs-1107949/v2

License: (c) (1) This work is licensed under a Creative Commons Attribution 4.0 International License. Read Full License 


\section{Abstract}

The widespread use of Additive Manufacturing (AM) has been extensively progressed in the past decade due to the convenience provided by AM in rapid and reliable part production. Fused Deposition Modeling (FDM) has witnessed even faster growth of application as its equipment is environmentally-friendly and easily adaptable. This increased use of FDM to manufacture prototypes and finished parts is accompanied by concerns that 3D printed parts do not perform the same as relatively homogeneous parts produced by molding or machining. As the interface between two faces of bonded material may be modeled by stress elements, in theory by modeling 3D printed layers subjected to tension at varying angles as transformed stress elements, the stress required to break the layer bonds can be determined. To evaluate such a relationship, in this study, the stresses calculated from stress transformation were compared with the behavior of 3D printed specimens subjected to tensile loads. The maximum principal stress was found to be constant relative to the layer angle, regardless of whether the specimen experienced failure at the layer interface or within the layer material, although the specimens with layers $75^{\circ}$ relative to the load were notable exceptions to this finding. This failure at much lower stresses for the samples used in the $75^{\circ}$ tests may be attributed to a possible environmental factor, such as temperature or humidity change, degrading the samples' structural integrity.

\section{Introduction}

Additive Manufacturing (AM) has improved the traditional method of part production through the elimination of several inner-process manufacturing steps, and post-processing like heat treatment [1-4]. The layer-by-layer production fashion of AM can fabricate parts with complicated geometries in a single-step process [5-10]. Researchers have extensively investigated the AM from different viewpoints in the past decade. Innovative methods for controlling the process temperature were experimented, which could take the material characteristics into account $[11,12]$. These methods were taken advantage of during production of electric components through ink writing [13]. Since the surface finish of printed parts was not favorable, adjusting different material thickness for various layers helped with creating high-quality parts with low surface roughness [14]. Also, deployment of tool path planning through addition of extruders to the system improved the quality of part, which caused a considerable difference in printing spherical geometries $[15,16]$. Fabrication of parts with such complex shapes results in material waste and long production time, which can be avoided by utilizing modular supports [17-20].

The ease of manufacture of components produced by Fused Deposition Modeling (FDM) out of Polymers makes them useful for rapid prototyping and scale testing of mechanisms and structures before mass-production or large-scale installation [21, 22]. In addition, considering the process impacts on both user-safety and the environment, the filament format of feedstock material to FDM process is less hazardous than the other formats of feedstock, such as powder in powder-based AM processes [23-26]. Before the advent of affordable FDM technology, prototypes may have been manufactured out of polymers using injection molding, which is both timeconsuming and expensive on smaller scales $[27,28]$. FDM allows parts with complex geometries to be rapidly manufactured cheaply, allowing designers to demonstrate and test the functionality of certain arrangements of parts [29].

A review on different aspects of the FDM process is given in [30], where the significant factors determining the quality of parts are discussed, out of which layer thickness was the most influential. Several researchers have also evaluated the tensile loads to investigate the effect of build orientation, raster angle, type of material, and impact speed on the mechanical properties and dimensional accuracy of parts fabricated by FDM [31]. By testing both single- and multi-layer specimens, the raster orientation was found an influential factor while the impact speed had limited effect [32]. In addition, the impact of build orientation on the parts' formation behavior was investigated in [33] by performing the tensile testing experiments on fabricated parts. These behaviors were also numerically studied with finite element analysis, results of which matched with those of experiments [34].

There is debate, however, as to the suitability of objects made using FDM as accurate representations of their production counterparts, in the realm of either AM or traditional manufacturing processes [35-39]. As FDM necessitates forming polymer filament into layers, the mechanical behavior under loading of the object at the layer boundaries may differ from the bulk behavior of the polymer that the part is composed of, making the part's loading behavior anisotropic $[40,41]$. While many manufacturers provide mechanical properties in the material specifications for their filament materials, the extensiveness of the documentation varies greatly in the tests performed and the print settings specified. For instance, while some filament manufacturers list filament's mechanical properties without mentioning the test standards or print settings, other manufacturers provide extensive documentation on test methods and print settings. Due to the planar nature of FDM, these documentations are still of limited use, as the relationship between the mechanical 
properties and the layer orientation is unclear. A mathematical model is required for determining such a relationship; the simplest representation can be the transformation of a stress element.

Experimentation has already been performed in the literature to determine the stress-strain behavior and tensile strength of parts manufactured by FDM under certain loading cases. However, only the extreme layer orientation angles were investigated. In this study, through examining the mechanical properties of parts fabricated with FDM at different layer orientations, the stress transformations were used to derive a stress-angle curve.

\section{Materials And Methods}

\subsection{Stress transformations}

An element of the 3D printed material at the layer interface may be represented by a 3D stress element, and as the stress on the surface of the part $\sigma_{z}$ may be neglected [42], it may instead be represented as a plane stress element as shown in Fig. 1a. When subjected to loads at varying layer orientations, the stress element at the layer interface may be represented by a transformed stress element as shown in Fig. 1b, with the forces acting on the stress element represented by the free-body diagram (FBD) in Fig. 1c.

As the test samples are considered to be in pure tension, $\sigma_{x}$ and $\tau_{x y}$ may also be neglected, leaving the stresses at the layer interface dependent on only the tensile stress $\sigma_{y}$ and layer orientation $\theta$ in Equations 1 through 3.

$$
\begin{gathered}
\sigma_{x^{\prime}}=\frac{\sigma_{y}}{2}-\frac{\sigma_{y}}{2} \cos 2 \theta \\
\sigma_{y^{\prime}}=\frac{\sigma_{y}}{2}+\frac{\sigma_{y}}{2} \cos 2 \theta \\
\tau_{x^{\prime} y^{\prime}}=\frac{\sigma_{y}}{2} \sin 2 \theta
\end{gathered}
$$

The stress transformation approach may be validated by comparing the maximum tensile stress developed at $\theta=90^{\circ}$ (tension normal to layers) to the transformed stress $\sigma_{x 1}$ developed at the layer interface for all other layer orientations. The validity of stress transformation will be verified if $\sigma_{y}$ at $\theta=90^{\circ}$ is equal to the transformed stress $\sigma_{x 1}$ normal to the layer for all layer orientations tested.

\subsection{Experimental Procedure}

Tensile tests were performed on Type I specimens modeled and tested according to the specifications from ASTM D638 [43, 44]. Three test specimens per orientation were fabricated to evaluate the results' repeatability. All test specimens were produced from $1.75 \mathrm{~mm}$ diameter PETG filament using an Anet A8 3D printer with the following printing parameters: $240^{\circ} \mathrm{C}$ printing temperature, $60^{\circ} \mathrm{C}$ heated bed temperature, $40 \mathrm{~mm} / \mathrm{s}$ print speed, $1.2 \mathrm{~mm}$ layer thickness, $100 \%$ infill density, and concentric infill pattern. The test specimens were produced with printed material layers oriented from $0^{\circ}$ to $90^{\circ}$ in $15^{\circ}$ increments, measured from normal to the direction of tension. Tensile tests were performed with an Instron 3365 tensile testing apparatus. The specimens were affixed between the grips of the tensile testing machine with a distance of $115 \mathrm{~mm}$ between the grips as specified in the ASTM D638, and they were tested under a motion rate of $3 \mathrm{~mm} / \mathrm{s}$.

\section{Results And Discussion}

Unlike most polymers, which usually experience a large amount of yield and elongation before breaking, most samples tested under the specified parameters of this study displayed a brittle fracture. Figure 2 shows the various stress-strain profiles of all of the test samples, grouped by the angle between the layer plane and the load. For angle $75^{\circ}$, while loads of each sample's failure were approximately equal, the extension of trial 1 reached just above $2.25 \mathrm{~mm}$ before failure, while the other two trials endured longer to extend to around $3.5 \mathrm{~mm}$ and $3.75 \mathrm{~mm}$.

Trial 2's specimen at $60^{\circ}$ failed at approximately half of the load and extension necessary to rupture the other two trials. This load was therefore considered an outlier and was not considered in calculations. The behavior of the specimen in Trial 3 at $0^{\circ}$ in Fig. 3 was 
particularly noteworthy, because instead of undergoing brittle fracture upon failure, it experienced ductile yielding with an elongation of over $28 \mathrm{~mm}$, and still did not experience complete separation. While its failure behavior was inconsistent with those of other specimens, the failure load was consistent with the other specimens of the set, and thus the strength of this particular sample was considered during calculation.

After obtaining the ultimate strengths of the samples at each layer angle, each set of ultimate strengths were averaged and plotted against the layer Angle relative to the load in Fig. 4.

The angle reference was switched from "relative to load" to "relative to the horizontal" axis for easier referencing later in the transformation equations. To find the related tensile stresses, these loads were utilized and were plotted in Fig. 5.

Using Eq. 1 to find the transformed stress $\sigma_{x^{\prime}}$ normal to the layer interface and plotting against the layer interface angle in Fig. 6 revealed that the stress was varying.

The remaining stresses $\sigma_{y^{\prime}}$ and $\tau_{x^{\prime} y^{\prime}}$ were calculated and plotted with $\sigma_{x^{\prime}}$ in Fig. 7.

Realizing that rather than experiencing single stress the layers were experiencing combined loading, the maximum principal stress for each layer angle was calculated using Eq. 4 and plotted in Fig. 8.

$\tau_{x^{\prime} y^{\prime}}=\frac{\sigma_{y}}{2} \sin 2 \theta$

This revealed that the maximum principal stress was the constant stress between all test specimens at around $38 \mathrm{MPa}$, except for the samples tested with layers printed at $75^{\circ}$ to the load, which consistently failed at much lower stresses.

\section{Conclusion}

In this study, Fused Deposition Modeling (FDM) Additive Manufacturing (AM) was used to fabricate parts with different layer orientations. Through examining the mechanical properties of fabricated parts, the stress transformations were used to generate a stress-angle curve. The stresses calculated from stress transformation were compared with the behavior of 3D printed specimens subjected to tensile loads. Based on the results, the initial hypothesis, that the transformation of a stress element could be validated if the calculated transformed stress $\sigma_{x^{\prime}}$ normal to the layer interface resulting from tensile tests was constant, was disproven. However, this was the result of failure to consider the other stresses acting at the layer interface rather than a fault in the principles of stress transformation, as the maximum principal stress resulting from the combined calculated transformed stresses relative to the layer angle was constant, regardless of whether the specimen experienced failure at the layer interface or within the layer material. The notable exceptions to this were the specimens with layers $75^{\circ}$ relative to the load. Noting the more pronounced striations along the samples used in the $75^{\circ}$ tests, it is possible that an environmental factor during printing, such as temperature or humidity change, may have been responsible for the degradation of the samples' structural integrity, causing them to fail at much lower stresses.

\section{Declarations}

\section{a. Funding}

No funds, grants, or other support was received.

b. Conflicts of interest/Competing interests

The authors declare that they have no conflict of interest.

c. Availability of data and material

The raw/processed data required to reproduce these findings will be made available on request.

d. Code availability

Not applicable 


\section{Compliance with ethical standards}

e. Ethics approval

The manuscript contains original ideas which have never been published before in other journals.

f. Consent to participate

This study is not a human transplantation study. No consent needed for this paper.

g. Consent for publication

The authors declare their consent for publication.

\section{References}

1. Sehhat MH, Mahdianikhotbesara A, Hadad M (2022) Formability Investigation for Perforated Steel Sheets, SAE Int. J. Mater. Manuf. 15 05-15-02-0012. https://doi.org/10.4271/05-15-02-0012

2. Mahdianikhotbesara A, Sehhat MH, Hadad M (2021) Experimental Study on Micro-Friction Stir Welding of Dissimilar Butt Joints Between Al 1050 and Pure Copper, Metallogr. Microstruct. Anal. (2021) 1-16. https://doi.org/10.1007/S13632-021-00771-5

3. Nezhadfar PD, Zarei-Hanzaki A, Sohn SS, Abedi HR, Characterization of twin-like structure in a ferrite-based lightweight steel,Met. Mater. Int. 2016225.22 (2016)810-816. https://doi.org/10.1007/S12540-016-6113-7

4. Sehhat MH, Mahdianikhotbesara A, Yadegari F (2021) Experimental Validation of Conductive Heat Transfer Theory: Thermal Resistivity and System Effects. Comput Res Prog Appl Sci Eng 7:1-6. https://doi.org/10.52547/CRPASE.7.4.2415

5. Sehhat MH, Behdani B, Hung C, Ali H (2021) Development of an Empirical Model on Melt Pool Variation in Laser Foil Printing Additive. Manufacturing Process Using Statistical Analysis

6. Hung CH, Chen WT, Sehhat MH, Leu MC (2020) The effect of laser welding modes on mechanical properties and microstructure of 304L stainless steel parts fabricated by laser-foil-printing additive manufacturing. Int J Adv Manuf Technol 1-11. https://doi.org/10.1007/s00170-020-06402-7

7. Hung C-H, Turk T, Sehhat MH, Leu MC (2022) Development and experimental study of an automated laser-foil-printing additive manufacturing system, Rapid Prototyp. https://doi.org/10.1108/RPJ-10-2021-0269. J. ahead-of-print

8. Turk T, Hung C-H, Hossein Sehhat M, Leu MC (2021) Methods of Automating the Laser-Foil-Printing Additive Manufacturing Process, https://doi.org/10.26153/TSW/17633

9. (8) The Transformative Potential of Additive Manufacturing I Request PDF, (n.d.). https://www.researchgate.net/publication/267517809_The_Transformative_Potential_of_Additive_Manufacturing

10. (8) Mechanical Properties of Parts Formed by Laser Additive Manufacturing I Request PDF, (n.d.). https://www.researchgate.net/publication/285853918_Mechanical_Properties_of_Parts_Formed_by_Laser_Additive_Manufacturing

11. Kundakcioglu E, Lazoglu I, Rawal S (2015) 851 Transient thermal modeling of laser-based additive manufacturing for 3D freeform structures, Int. J. Adv. Manuf. Technol. 85 (2015) 493-501. https://doi.org/10.1007/S00170-015-7932-2

12. Kundakcıoğlu E, Lazoglu I, Poyraz Ö, Yasa E, Cizicioğlu N (2018) 959 Thermal and molten pool model in selective laser melting process of Inconel 625, Int. J. Adv. Manuf. Technol. 95 (2018) 3977-3984. https://doi.org/10.1007/S00170-017-1489-1

13. Khan SA, Lazoglu I (2019) Development of additively manufacturable and electrically conductive graphite-polymer composites. Prog Addit Manuf 2019 52:153-162. https://doi.org/10.1007/S40964-019-00102-9

14. Isa MA, Lazoglu I (2019) Five-axis additive manufacturing of freeform models through buildup of transition layers. https://doi.org/10.1016/j.jmsy.2018.12.002

15. Yigit IE, Lazoglu I, Lazoglu I (2019) Helical slicing method for material extrusion-based robotic additive manufacturing 5-axis Additive Manufacturing System View project Development of An Open-Architecture Rapid Prototyping System View project Helical slicing method for material extrusion-based robotic additive manufacturing, 4 225-232. https://doi.org/10.1007/s40964-01900090-w

16. Yigit IE, Lazoglu I (2020) Spherical slicing method and its application on robotic additive manufacturing. Prog Addit Manuf 2020 54:387-394. https://doi.org/10.1007/S40964-020-00135-5

Page 5/12 
17. Yigit IE, Isa M, Lazoglu I (2018) Additive Manufacturing with Modular Support Structures, https://doi.org/10.26153/TSW/17208

18. Isa MA, Yiğit IE, Lazoglu I (2018) Analysis of Build Direction in Deposition-Based Additive Manufacturing of Overhang Structures, https://doi.org/10.26153/TSW/17156

19. Yigit IE, Lazoglu I (2019) Dynamic Build Bed for Additive Manufacturing, https://doi.org/10.26153/TSW/17381

20. Yigit IE, Khan SA, Lazoglu I, Yigit IE, Khan SA (2022) Robotic Additive Manufacturing of Tooling for Composite Structures Development of An Open-Architecture Rapid Prototyping System View project Additive Manufacturing with Funtional Materials View project ROBOTIC ADDITIVE MANUFACTURING OF TOOLING FOR COMPOSITE STRUCTURES, (n.d.). https://www.researchgate.net/publication/345921432

21. Behdani B, Senter M, Mason L, Leu M, Park J (2020) Numerical Study on the Temperature-Dependent Viscosity Effect on the Strand Shape in Extrusion-Based Additive Manufacturing. J Manuf Mater Process 4:46. https://doi.org/10.3390/jmmp4020046

22. Sehhat MH, Mahdianikhotbesara A, Yadegari F (2021) Impact of Temperature and Material Variation on Mechanical Properties of Parts Fabricated with Fused Deposition Modelling (FDM) Additive Manufacturing. https://doi.org/10.21203/RS.3.RS-1079840/V1

23. Sehhat MH, Mahdianikhotbesara A (2021) Powder spreading in laser-powder bed fusion process, 2389. https://doi.org/10.1007/s10035-021-01162-x

24. Sehhat MH, Chandler J, Yates Z (2021) A review on ICP powder plasma spheroidization process parameters. Int J Refract Met Hard Mater 105764. https://doi.org/10.1016/J.IJRMHM.2021.105764

25. Sehhat MH, Sutton AT, Hung C-H, Newkirk JW, Leu MC (2021) Investigation of Mechanical Properties of Parts Fabricated with Gasand Water-Atomized 304L Stainless Steel Powder in the Laser Powder Bed Fusion Process, JOM 2021. 1-8. https://doi.org/10.1007/S11837-021-05029-7

26. Liu T, Lough CS, Sehhat H, Huang J, Kinzel EC, Leu MC (2021) In-Situ Thermographic Inspection for Laser Powder Bed Fusion, in: 2021 Int. Solid Free. Fabr. Symp., University of Texas at Austin,

27. Liou A-C, Chen R-H (2006) Injection molding of polymer micro-and sub-micron structures with high-aspect ratios. Int J Adv Manuf Technol 28:1097-1103. https://doi.org/10.1007/s00170-004-2455-2

28. Su YC, Shah J, Lin L (2003) Implementation and analysis of polymeric microstructure replication by micro injection molding. J Micromechanics Microengineering 14:415. https://doi.org/10.1088/0960-1317/14/3/015

29. Esposito Corcione C, Gervaso F, Scalera F, Montagna F, Sannino A, Maffezzoli A (2017) The feasibility of printing polylactic acidnanohydroxyapatite composites using a low-cost fused deposition modeling 3D printer. J Appl Polym Sci 134:44656. https://doi.org/10.1002/APP.44656

30. Syrlybayev D, Zharylkassyn B, Seisekulova A, Akhmetov M, Perveen A, Talamona D (2021) Optimisation of Strength Properties of FDM Printed Parts-A Critical Review, Polymers (Basel). 13. https://doi.org/10.3390/POLYM13101587

31. Messimer SL, Pereira TR, Patterson AE, Lubna M, Drozda FO (2019) J Manuf Mater Process 2019 3(3):6. Page 6https://doi.org/10.3390/JMMP3010006. Full-Density Fused Deposition Modeling Dimensional Error as a Function of Raster Angle and Build Orientation: Large Dataset for Eleven Materials,

32. Casavola C, Cazzato A, Moramarco V, Renna G (2019) Mechanical behaviour of ABS-Fused Filament Fabrication compounds under impact tensile loadings. Mater (Basel) 12. https://doi.org/10.3390/MA12081295

33. Hambali RH, Smith P, Rennie AEW (2012) Determination of the effect of part orientation to the strength value on additive manufacturing FDM for end-use parts by physical testing and validation via three-dimensional finite element analysis. Int J Mater Eng Innov 3:269-281. https://doi.org/10.1504/IJMATEl.2012.049266

34. Rafi AH, Ahmed DH (2022) Two-dimensional analogies to the deformation characteristics of a falling droplet and its collision. 0-2. https://doi.org/10.24425/ame.2021.139649

35. Nezhadfar PD, Thompson S, Saharan A, Phan N, Shamsaei N (2021) Structural integrity of additively manufactured aluminum alloys: Effects of build orientation on microstructure, porosity, and fatigue behavior. Addit Manuf 47:102292. https://doi.org/10.1016/J.ADDMA.2021.102292

36. Nezhadfar PD, Shamsaei N, Phan N (2021) Enhancing ductility and fatigue strength of additively manufactured metallic materials by preheating the build platform. Fatigue Fract Eng Mater Struct 44:257-270. https://doi.org/10.1111/FFE.13372

37. Jirandehi AP, Chakherlou TN (2019) A fatigue crack initiation and growth life estimation method in single-bolted connections. J Strain Anal Eng Des 54:79-94. https://doi.org/10.1177/0309324719829274 
38. Ghadimi H, Jirandehi AP, Nemati S, Guo S (2021) Small-sized specimen design with the provision for high-frequency bendingfatigue testing, Fatigue Fract. Eng Mater Struct. https://doi.org/10.1111/FFE.13589

39. Mahdianikhotbesara A, Sehhat MH, Hadad M Experimental study on micro friction stir welding of dissimilar butt joints between Al 1050 and pure copper, (n.d.). https://doi.org/10.1007/s13632-021-00771-5

40. Ziemian C, Sharma M, Ziemian S (2021) 7 Anisotropic Mechanical Properties of ABS Parts Fabricated by Fused Deposition Modelling, (n.d.).

41. Yadegari F, Sehhat MH, Mahdianikhotbesara A, A Numerical Study of Automotive Body Panel Draw Dies Defects Using Finite Element Simulation (2022), https://doi.org/10.21203/RS.3.RS-1300589/V1

42. Mechanics of Materials (2021) : Stress Transformation » Mechanics of Slender Structures | Boston University, (n.d.). https://www.bu.edu/moss/mechanics-of-materials-stress-transformation/

43. ASTM D638-14 Standard Test Method for Tensile Properties of Plastics (2021) (n.d.). https://www.astm.org/Standards/D638

44. Lanzotti A, Grasso M, Staiano G, Martorelli M (2015) The impact of process parameters on mechanical properties of parts fabricated in PLA with an open-source 3-D printer. Rapid Prototyp J 21:604-617. https://doi.org/10.1108/RPJ-09-20140135/FULL/XML

\section{Figures}

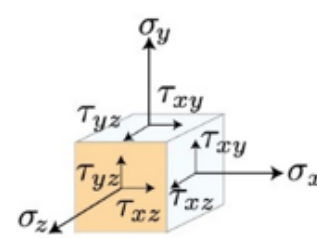

3D Stress State

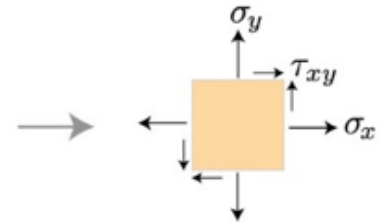

Plane Stress
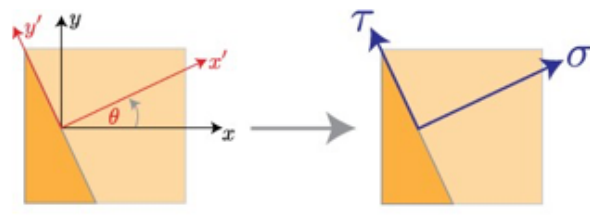

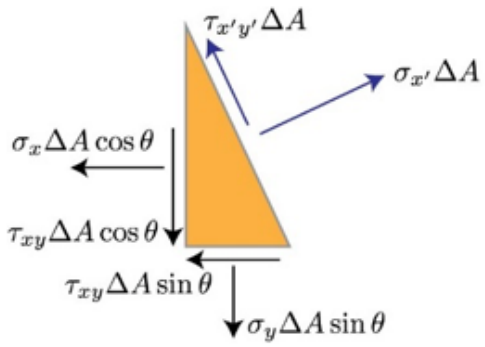

\section{Figure 1}

(a) 3D and Plane Stress Element, (b) Stress Transformation of Plane Stress Element, (c) Transformed Stress Element FBD. 
Load vs Extension - 90 Degrees

—Trial 1 -Trial 2 - Trial 3

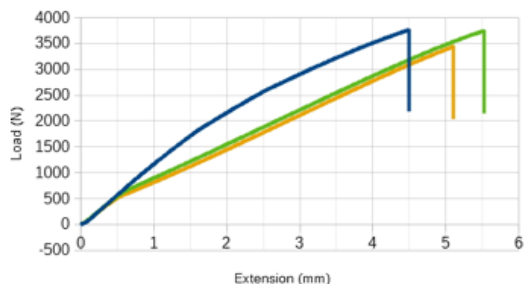

(a)

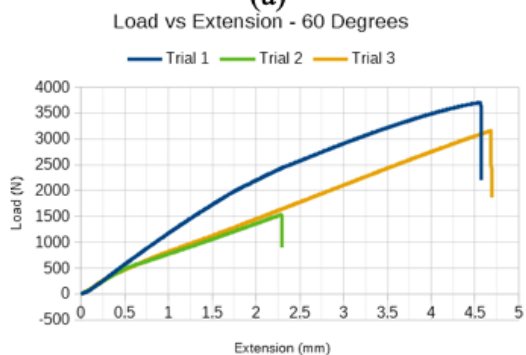

(c)

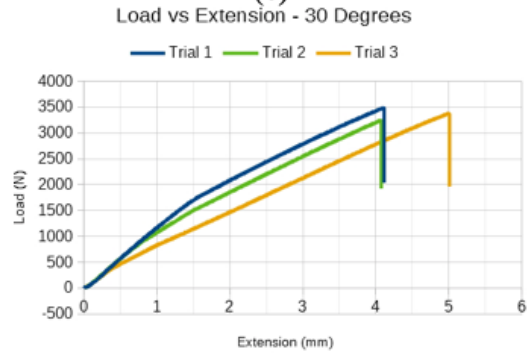

(e)

Load vs Extension - 0 Degrees

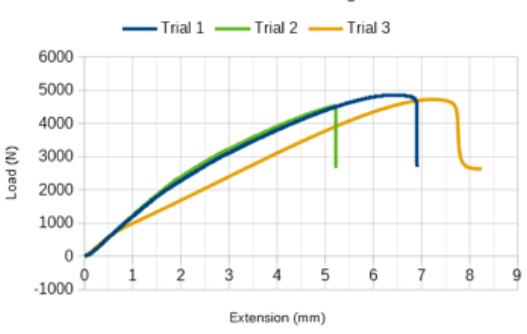

(g)

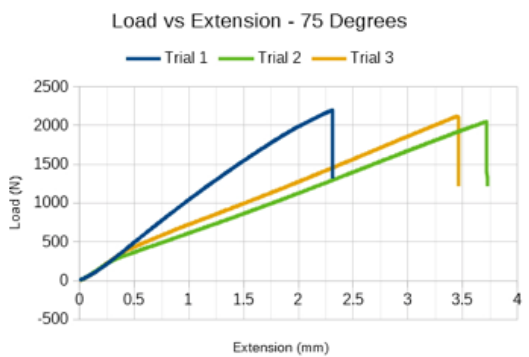

(b)

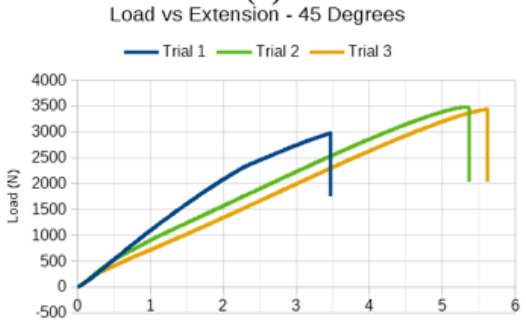

(d)

Load vs Extension - 15 Degrees

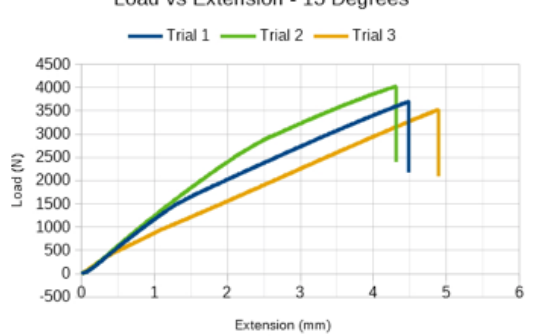

(f)

\section{Figure 2}

Stress-Strain curves were obtained from samples with layers (a) perpendicular to the load, (b) $75^{\circ}, 60^{\circ}, 45^{\circ}, 30^{\circ}, 15^{\circ}$, and parallel to the load. 


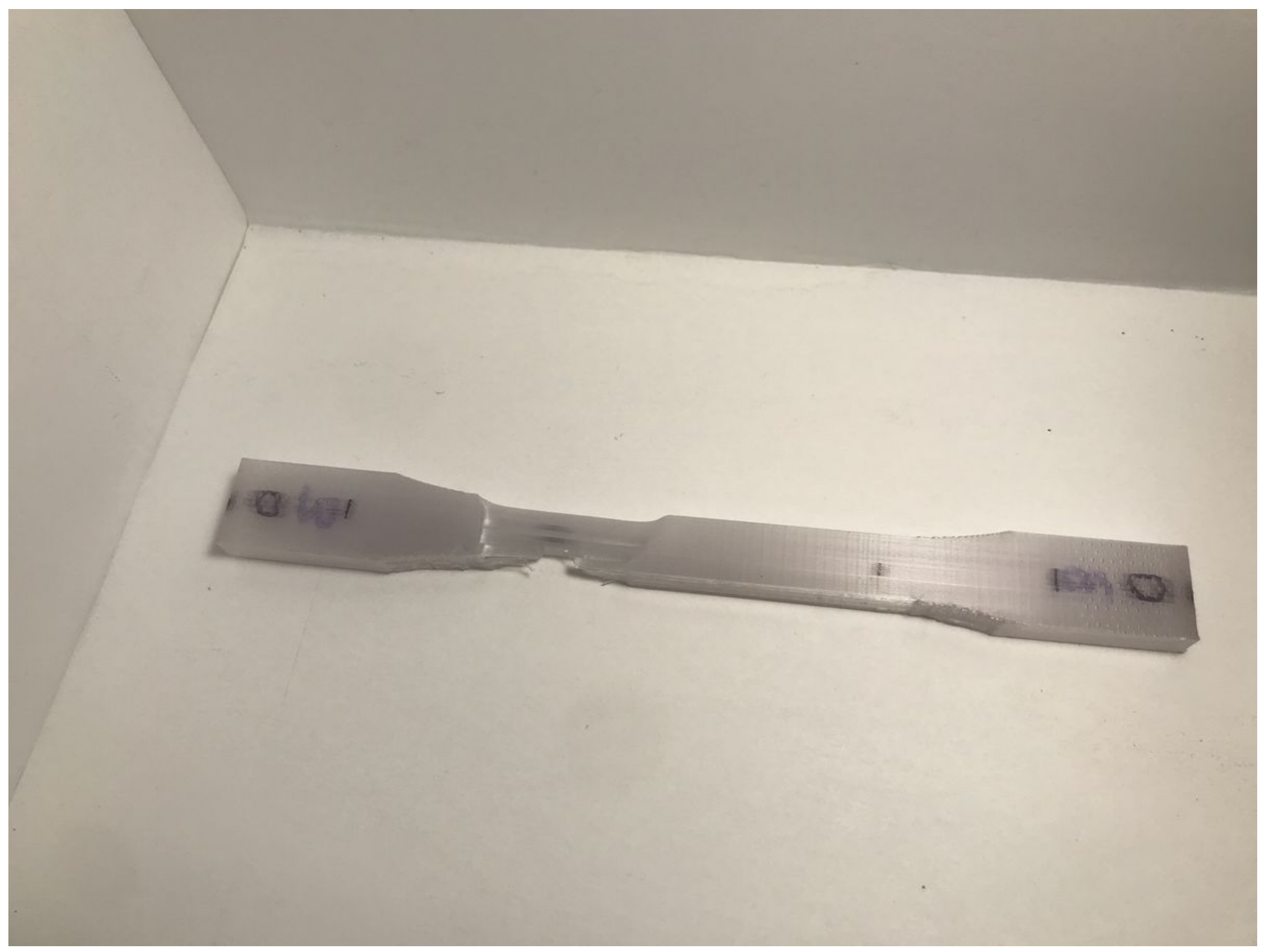

\section{Figure 3}

Ductile failure of sample 3 taken at $0^{\circ}$. 


\section{Average Maximum Load vs Layer Angle (Relative to Load)}

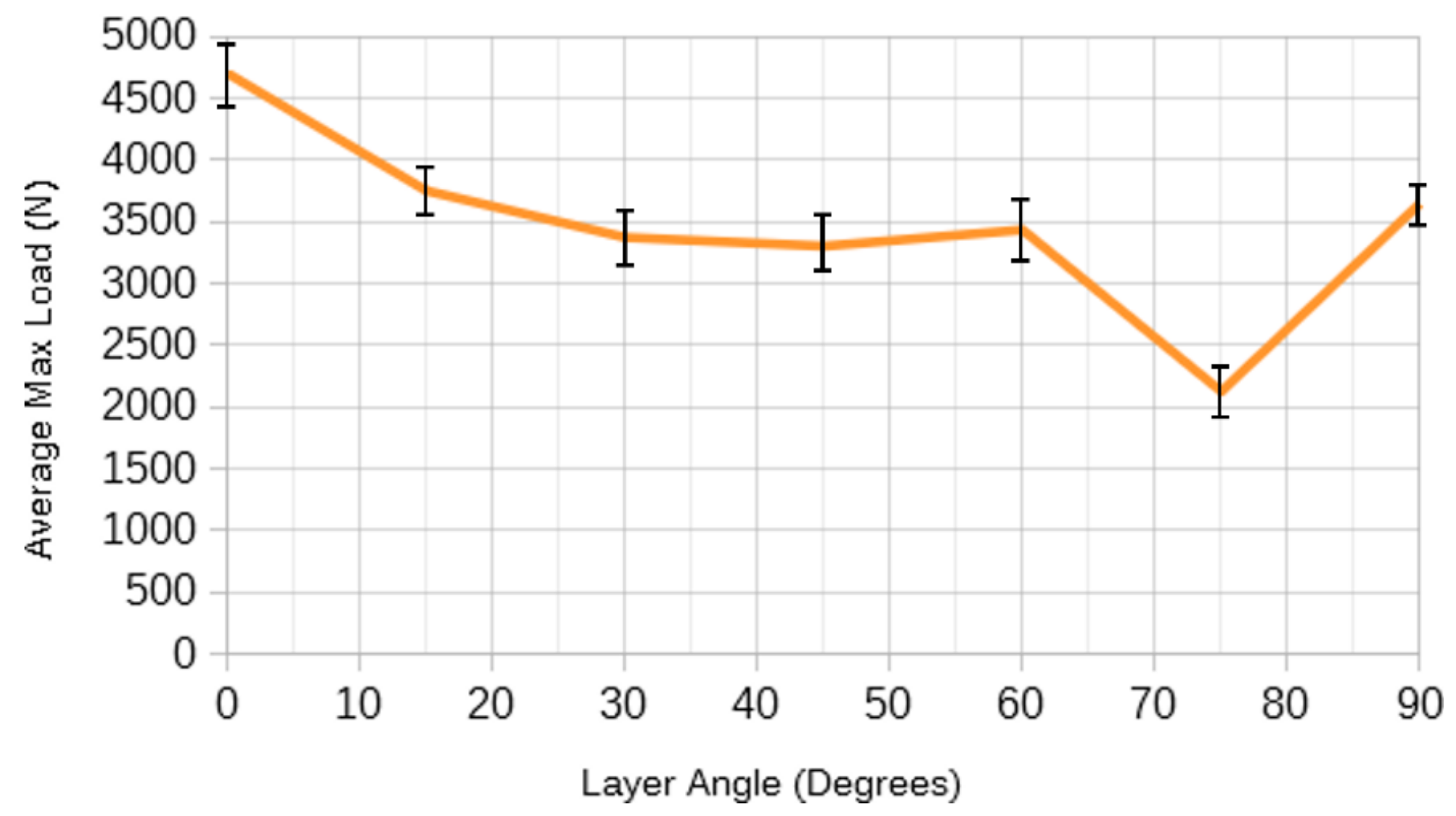

Figure 4

Average Maximum Stress vs Layer Angle.

Average Maximum Load and Tensile Stress vs Layer Angle

(Relative to Horizontal)

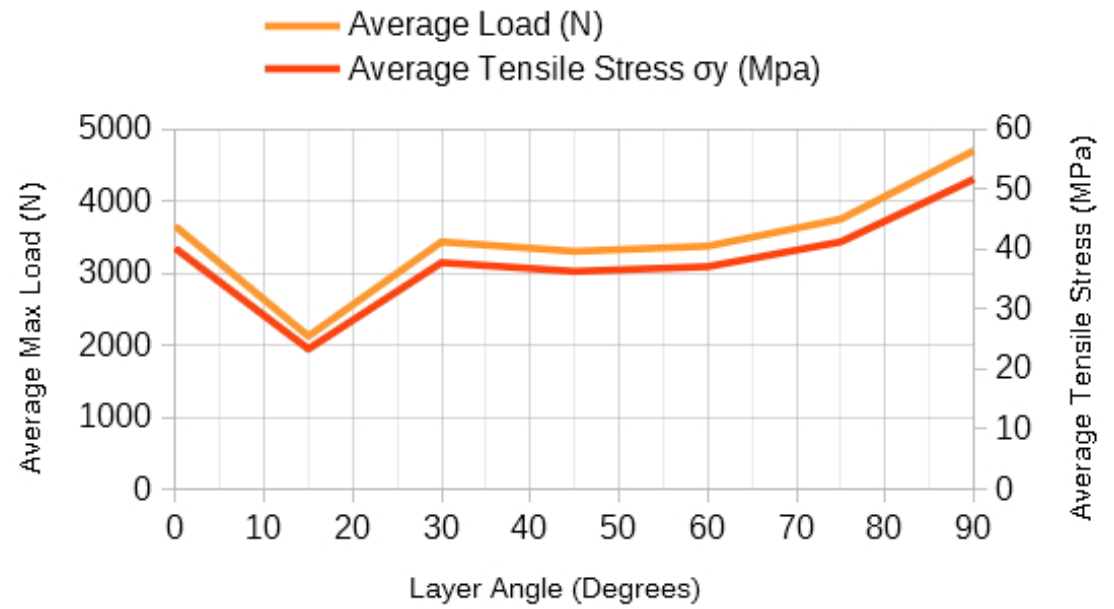

Figure 5

Specimen Failure Load and Tensile Stress vs Layer Angle. 


\section{Average Transformed Stress $\sigma x^{\prime}$ vs Layer Angle (Relative to Horiz ontal)}

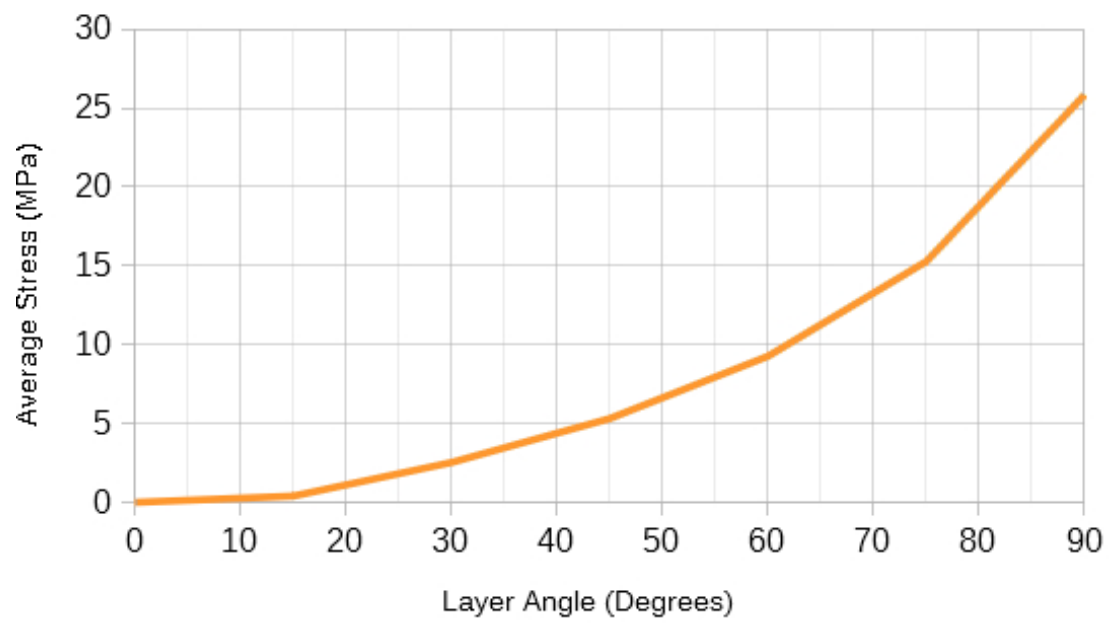

\section{Figure 6}

Transformed Normal Stress vs Layer Angle.

\section{Average Transformed Stresses vs Layer Angle} (Relative to Horizontal)

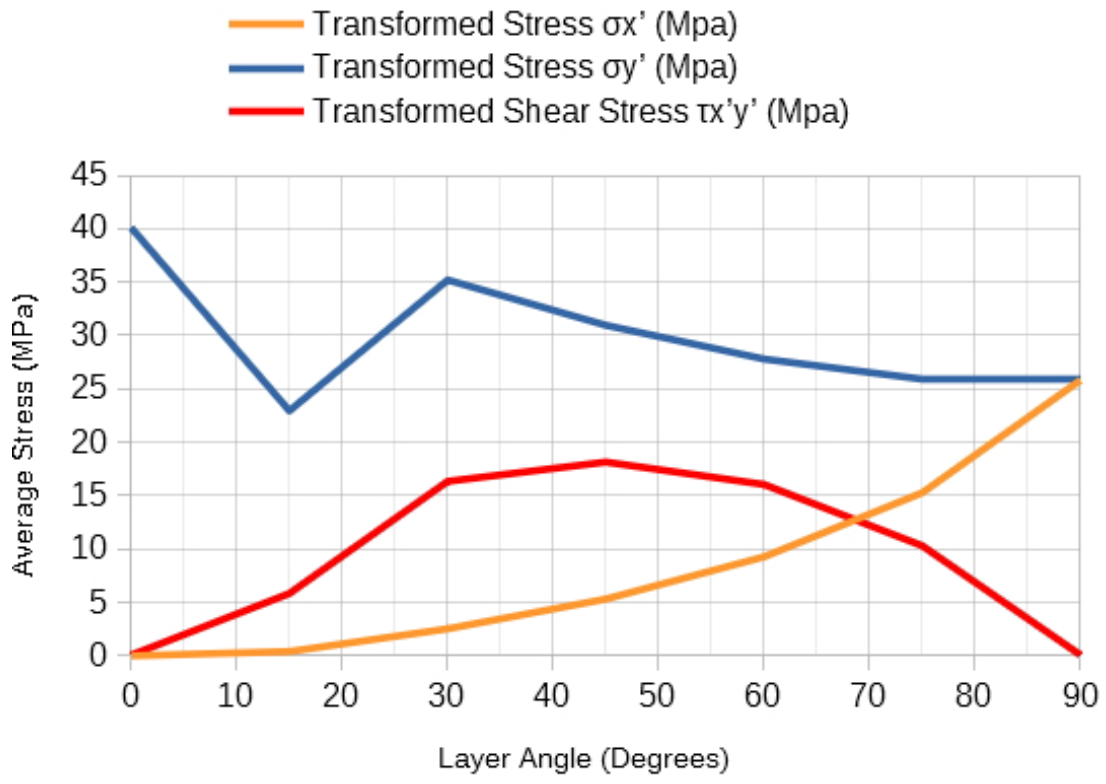

\section{Figure 7}

Transformed Stresses vs Layer Angle. 


\section{Maximum Transformed Principle Stress vs Layer Angle (Relative to Horizontal)}

- Average Maximum Transformed Principle Stress (Mpa)

_ Ideal Average Maximum Transformed Principle Stress (Mpa)

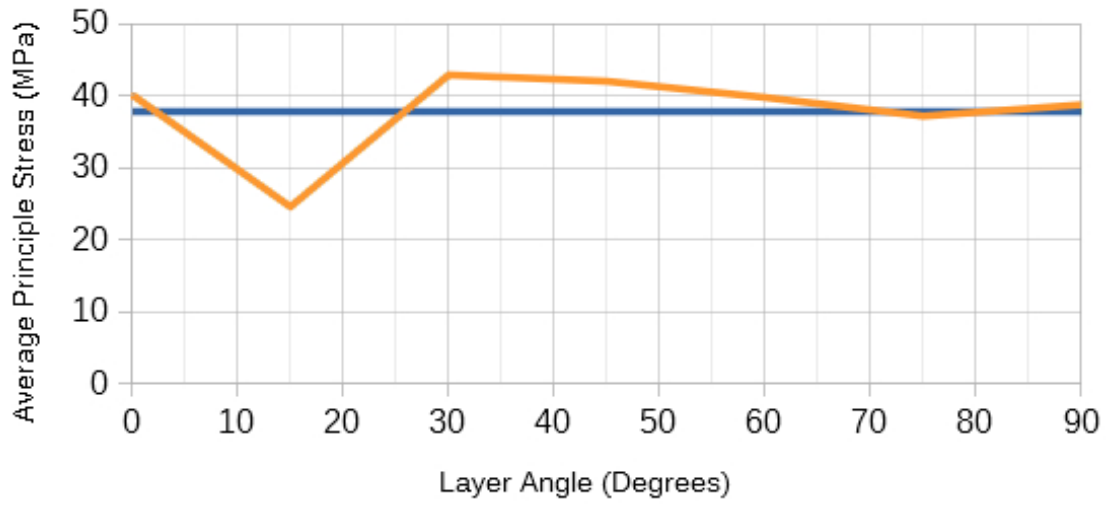

\section{Figure 8}

Transformed Principal Stress vs Layer Angle. 